\title{
Andreas Weiglein: exceptional teacher and scientist not only for Graz
}

\author{
Georg Feigl \\ Department of Macroscopic and Clinical Anatomy, Medical University of Graz, Graz, Austria \\ Anatomy 2020;14(1):1-2 @2020 Turkish Society of Anatomy and Clinical Anatomy (TSACA)
}

Andreas Weiglein - Anatomists all over the world know this name very much. His death in February 2020 was a shock and tragedy, although many of the anatomical community knew about his illness and his suffer. Despite the tragic end, let's highlight this person and honor him respectfully in a different way. Not about numbers of publications, not about the regularly known stories, I want to present some personal key-moment with Andreas.

Andreas Weiglein studied at the Karl Franzens University in Graz and became Studying Assistant at the Institute of Anatomy. At that time, the head of Department was Professor Thiel, who is also well known due to his developed embalming procedure. Under his "mentor" Professor Anderhuber, he became assistant and was assisted and supervised in his early career. When he received the "Venia docendi", he already was known in the English-speaking countries. He attended the meetings of the AACA and AAA frequently, also won prizes for "Best lectures". Memorable as his style of lectures, presenting with an easiness and high standard. When myself saw him as a presenter for the first time at a meeting of the International Society of Plastination (ISP) in Knoxville, $\mathrm{TN}$, in 1997 and at a ACA meeting in Lexington, KY, in 1998, I was deeply moved and impressed about the way of his presentations, the standard and the clinical background of his scientific work. He became an idol, to work hard and to try the best in presenting our scientific work on an international platform. What is more, he was a respected person with high reputation at that time. In addition, we always highlighted the affiliation to the University of Graz and was proud to be part of the Institute. All the upcoming years, he surprised with new investigations and never rested to support young colleagues not only from the own Institute, such as myself, but especially encouraged young

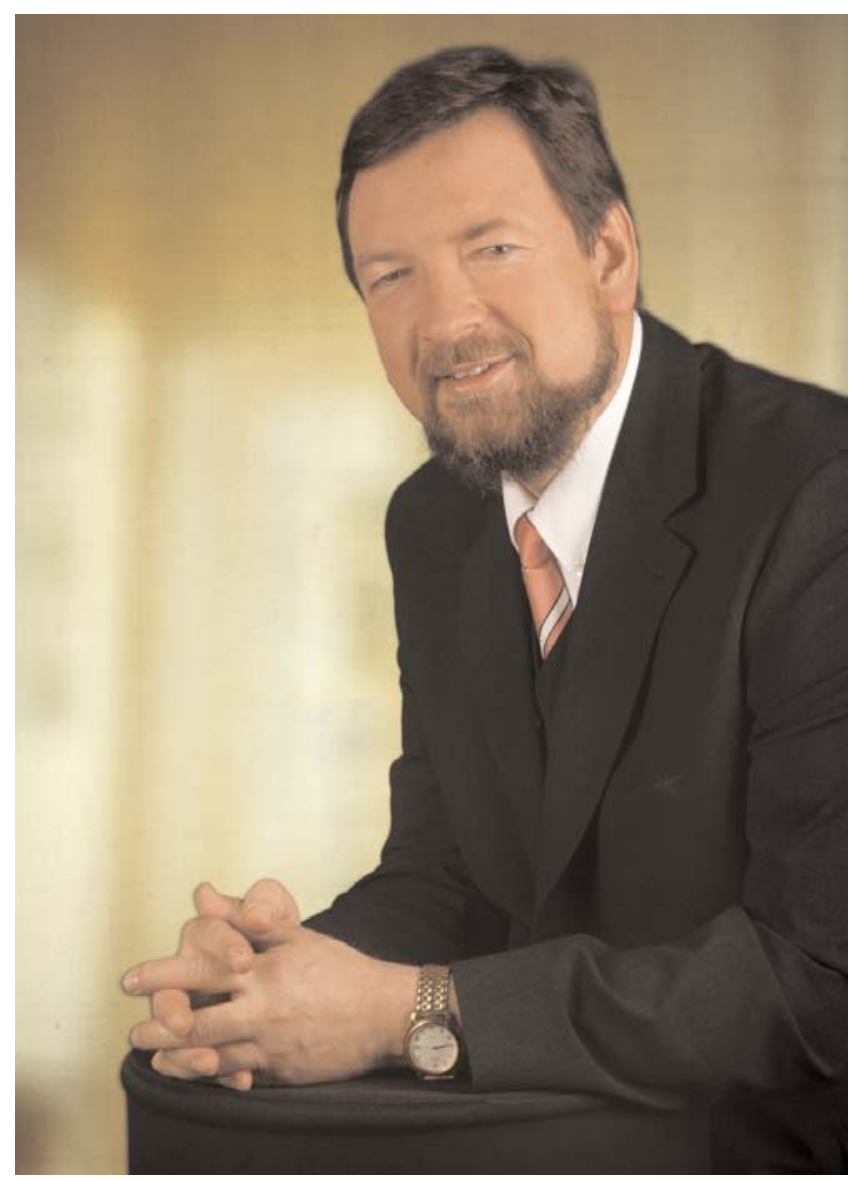

Figure 1. Andreas Weiglein (1961-2020), Professor of Anatomy and Vice Chairman, Institufe of Anatomy, Medical University Graz, Austria.

scientists to come to Graz. Many visits were enforced by Andreas' support, many of our, nowadays experienced scientists still remember unforgettable moments in Graz and worldwide at meetings and during the gala dinners or spouse programs. 


\section{Feigl G}

Science is one part of the anatomist's work. Teaching is the other also important part. I was lucky to be able to assist his lectures many years. He was one of the professors, who was able to present almost any topic of the human body without any prior preparation. I always have kept in mind one moment: he landed in Graz, returning from a conference which was held in the United States, took a taxi and went straight to.... not home but to University to do a lecture about the inner ear. When arriving, about five minutes were left and he asked for water and entered the lecture hall. In there, he asked us as assistants: "Please give me a keyword, where we stopped last lecture!" started an anatomical firework.

ORCID ID:

G. Feigl 0000-0001-6984-5413

deomed.
All his work, his love to dissect and to teach he kept until the very end. Although he suffered a lot because of his illness, he never gave up. When I ruled the Department of Macroscopical and Clinical Anatomy as an interims HoD, I often took his advice due to his experience and passion on Anatomy. The passion and his spirit, which infiltrated so many of us and encourage us in becoming a better teacher, better scientist and better anatomist daily.

Andreas, thank you for all moments; thank you for the time we could share; thank you for being a personal highlight and unforgettable professor of our anatomical community.

Requiescat in pace!

Correspondence to: Georg Feigl, MD, Sen. Lect. Priv. Doz. FA Dr. med. Univ Department of Macroscopic and Clinical Anatomy, Medical University of Graz, Graz, Austria

Phone: +43699 11112460

e-mail: feigl.georg@gmx.at

Conflict of interest statement: No conflicts declared.

This is an open access article distributed under the terms of the Creative Commons Attribution-NonCommercial-NoDerivs 3.0 Unported (CC BY-NCND3.0) Licence (http://creativecommons.org/licenses/by-nc-nd/3.0/) which permits unrestricted noncommercial use, distribution, and reproduction in any medium, provided the original work is properly cited. Please cite this article as: Feigl G. Andreas Weiglein: exceptional teacher and scientist not only for Graz. Anatomy 2020;14(1):1-2. 